\title{
Remote Sensing and GIS based Mapping of Clay Soils- A Case Study of Patna District, Bihar, India
}

\author{
Binod Kumar Vimal ${ }^{1}$, Sunil Kumar ${ }^{1 *}$, Amit Kumar Pradhan ${ }^{1}$, Ragini Kumari ${ }^{1}$, \\ Hena Parveen ${ }^{1}$ and Sanjeev Kumar Gupta ${ }^{2}$ \\ ${ }^{1}$ Department of Soil Science and Agricultural Chemistry, Bihar Agricultural University, \\ Sabour-813210, Bhagalpur, Bihar, India \\ ${ }^{2}$ Department of Agronomy, Bihar Agricultural University, Sabour-813210, Bhagalpur, \\ Bihar, India
}

*Corresponding author

\section{A B S T R A C T}

\section{Keywords}

Clay soils, NDVI, NIR band, Tal and RS-GIS

Article Info

Accepted:

04 March 2019

Available Online:

10 April 2019
Developed model is based on digital image processing techniques under RS-GIS domain, in which conversion of Intensity, Hue and Saturation to RGB image of SWIR, NIR and red spectral bands has been applied for the signature capture of clay soils. To achieve this target, spectral enhancement process was initiated by using of AWiFS data (May, 2015). Clear cut demarcation of clay soil patches from surrounding was observed in blue tone of the converted RGB image. Out of the total geographical area, the maximum coverage of clay soils was observed in Mokama (12.79\%) followed by Pandarakh (11.12\%), Ghoswari $(10.48 \%)$, Pali $(10.46 \%)$ and Bakhtiyarpur $(9.90 \%)$ blocks. However, in context of physicchemical status of soils, the clay content varied from 57 to $66 \%$, soil pH neutral to slightly alkaline (7.02.-8.62), EC normal, available nitrogen low, available phosphate medium and available potash medium to high were recorded. Research findings may be helpful for the confirmation of heavy texture soils under low land topography of Bihar.

\section{Introduction}

The soils are valuable natural resources which are directly associated with agricultural production. In low land ecology of river Ganga basins, clay soils are locally known as Tal, and Chour may be perceived. Tree less ecology and Rabi cropping system are the general features found in heavy clay soils. In this context, soil survey towards agricultural land use planning is an important parameter for the sustainability of agriculture practices. (Manchanda et al., 2002) reported that survey data provided adequate information in terms of land forms; natural vegetation as well as characteristics of soils which can be utilized for management of land resource management. In case of soil resource mapping, mid-IR soil spectra has a stronger signal that is built in portable instrumentation and can be easily used in the field and direct links can be made with hyper-spectral remote 
sensing (Gomez et al.,2008). Similarly, (Kristof et al., 1980) reported that the spectral reflectance response is the result of numerous soil properties and that the spectrally-derived maps may delineate important information about surface soil conditions. Viscarra et al., (2009) reported that iron oxides, clay minerals and soil colour can be measured directly from the spectra which are governed by incident or reflected energy. Spectral response based technologies like remote sensing, allowed the data discrimination between crop residues and soil, distinguishing iron oxides, iron hydroxides and iron sulphates, and distinguishing between clay and sulphate mineral species (Hubbard et al., 2003) In order to obtain a more accurate interpretation using satellite data, several empirical radiometric indices have been proposed, such as, a 'redness index', a 'colour index' and a 'texture index' (Pouget et al.,1990). Present day, signature capture of perfect tone of the soils or spectral responses of the target from satellite images is a researchable issue, and keeping this in view; the main objective of the present study was to capture the perfect tone of clay soils by using conversion of Intensity Hue and Saturation to RGB under spectral enhancement techniques of satellite data for Patna district of Bihar.

\section{Materials and Methods}

The Patna district falls between $25^{\circ} 12^{\prime}$ to 25 ${ }^{\circ} 44^{\prime} \mathrm{N}$ latitudes and $84^{\circ} 40^{\prime}$ to $86^{\circ} 04^{\prime} \mathrm{E}$ longitudes in Bihar. As reported in the administrative atlas of Bihar (2001), the district encompasses a total geographical area of $3130 \mathrm{~km}^{2}$ and is divided into 23 blocks. Due to well concentration of heavy textured soils in Maranchi Tal, Mokameh block was selected for field survey, soil sampling and visual interpretation of the satellite image with respect to appearance of clay (Tal) soils.(Zhang et al., 2014) reported that mapping of land use/land cover pattern are extracted more accurately by visual interpretation than by digital classification. Field survey was done during the month of February, 2015 and randomly ten locations that was directly associated with heavy clay soil patches ( $>65 \%$ clay) were selected in Maranchi Tal with GPS reading for the collection of soil samples and their textural analysis, visual interpretation and image enhancement of the satellite image. Remotely sensed data require certain amount of field observation called "ground truth" in order to convert it into meaningful information. Such work involved visiting a number of test sites, usually taking the satellite data and its derived data. Different locations of Ghoswari, Barh, Bakhatiyarpur and Paliganj blocks were selected for the validation of results. Over this concern, GPS receiver and derived data with respect to confirm the clay soils by using developed tone, interpreted digital values and analysed report of soils samples were used. Topographical maps, documented soil survey reports and ancillary data were also used for reference purposes during validation of research findings.IRS, AWiFS (2015) data having four spectral bands; green (0.52$0.59 \mu \mathrm{m})$, red $(0.62-0.68 \mu \mathrm{m})$, Near Infra Red $(0.77-0.86 \mu \mathrm{m})$ and Short Wave Infra Red $(1.55-1.70 \mu \mathrm{m})$ and having $56 \mathrm{~m}$ spatial resolution (Singh et al., 2009) was used for the visual interpretation and spectral enhancement towards signature capture of clay soils. Geospatial software viz. TNT Mips, Erdas Imagine, ENVI 5.1 and Arc GIS10.1 were used for digital image processing and mapping.

The Normalized Difference Vegetation Index (NDVI) was used to measure the vegetative cover on the land surface over wide areas and confirmation of the tree less ecology under clay soils. The NDVI, introduced in the early seventies by (Rouse et al., 1973) is expressed as the difference between the near infrared (NIR) and red bands (RED) normalized by the 
sum of those bands Normalised Difference Vegetation Index $($ NDVI $)=($ NIR - Red $) /$ (NIR + Red) where R-NIR is the reflectance in the Near Infra Red (NIR) and G-RED is the reflectance in the RED part of the electromagnetic spectrum. Mechanical analysis of collected soil samples from clay soil environment was done using standard procedure. The mechanical analysis of soil separates followed by International pipette method. The $\mathrm{pH}$ and EC was analyzed as per the standard procedure (Jackson, 1973) The $^{\circ}$ available nitrogen, $\mathrm{P}$ and the available $\mathrm{K}$ were extracted by using Normal ammonium acetate and the content was determined by aspirating the extract into flame photometer. Details of methodology towards visual interpretation and spectral enhancement processes are being summarised in given flow chart (Fig. 1).

\section{Results and Discussion}

Clay soils appeared dark bluish and healthy vegetation red in false colour composite (FCC) image of NIR, red and green bands (Fig. 2). Healthy vegetation appears green in layer stacked blue, green and red bands due to high reflectance of green energy comparison to blue and red (Lillesand et al.,2005), means red objects appeared red in same layer stacked bands. Over this concern, variation of tone in different bands provided a clue for the signature capture of the target and conversion of Intensity, Hue and Saturation (IHS) to Red, Green and Blue (RGB) image by using of MIR, NIR and red bands was applied to trace out the distinct tone (blue) for those pixels that were directly associated with clay soil patches (Fig. 5). RGB colours and their mixed components in the image are associated with Intensity Hue-Saturation (IHS) system where Intensity relates to the total brightness of a colour, Hue refers to the dominant or average wavelength of light contributing to a colour and Saturation specifies the purity of colour relative to gray e.g. solid pink has low saturation than the solid crimson. RGB+IHS yielded values provided very high accuracies for the calculation of the texture of the objects (Laliberte and Rango,2008), means the spectral information of the target is separated into the hue and saturation components under three-color composite image from the original image data using Multispectral transformation (Carper et al.,1990). When light hits the object, some wavelengths (energy) are reflected and received by satellite sensors means if the radiation arriving at the sensor, is measured at many wavelengths and that variation of spectrum can be used to identify the materials in a scene and discriminate among different classes of material (Gary et al.,2003). Randomly ten soil samples with GPS reading (latitudes and longitudes) from well known patches of clay soils of Maranchi, Mokameh and Bakhtiarpur tal were taken for the analysis of soil texture, $\mathrm{pH}$ and EC. Similarly, False Colour Composite image (IRS- AWiFS) for the same locations was also interpreted for the spectral analysis of clay soil patches (Fig. 3). Digital values having spectral graphs of layer stacked MIR, NIR; red and green bands corresponding to comparative study of the clay soils, sand patches and water bodies were analysed (Fig. 4). As per analyzed reflectance curve, reflectance of clay soils comparison to water bodies was high in MIR and NIR bands but low in case of sand patch (Fig. 4). In both cases, distinction in spectral responses provided a clue for the separation of clay soils from surrounding. Based on interpretation of NDVI, appearance of vegetation (Range $<0.1$ ) was very low under clay soils that indicated the tree less ecology (Fig. 5). Spectral enhancement technique was applied for the conversion of IHS to RGB by using digital image processing software and finally natural blue tone (distinct result of clay soil patches) was came out (Fig. 5). 
Table.1 The physico-chemical properties of clay soils

\begin{tabular}{|c|c|c|c|c|c|c|c|c|c|c|c|}
\hline \multirow[t]{3}{*}{ S.No. } & \multirow[t]{3}{*}{ Latitudes } & \multirow[t]{3}{*}{ Longitudes } & \multicolumn{9}{|c|}{$\begin{array}{l}\text { Observed data } \\
\text { satellite data and textural analysis of the soil samples) }\end{array}$} \\
\hline & & & Sand & Silt & Clay & \multirow{2}{*}{$\begin{array}{l}\text { Soil Texture } \\
\text { class }\end{array}$} & \multirow{2}{*}{$\underset{(1: 2.5)}{p H}$} & \multirow{2}{*}{$\begin{array}{c}\text { EC } \\
(\mathrm{dSm}-1)\end{array}$} & \multirow{2}{*}{$\begin{array}{l}\text { Avail. N } \\
\text { (Kg/ha) }\end{array}$} & \multirow{2}{*}{$\begin{array}{c}\text { Avail. } \mathbf{P}_{2} \mathrm{O}_{5} \\
\text { (Kg/ha) }\end{array}$} & \multirow{2}{*}{$\begin{array}{c}\text { Avail. } \mathrm{K}_{2} \mathrm{O} \\
(\mathrm{Kg} / \mathrm{ha})\end{array}$} \\
\hline & & & \multicolumn{3}{|c|}{$(\%)$} & & & & & & \\
\hline 1 & $25^{0} 19^{\prime} 15^{\prime \prime}$ & $85^{0} 58^{\prime} 56^{\prime \prime}$ & 9.21 & 25.63 & 65.16 & Clayey & 7.79 & 0.18 & 150.52 & 36.00 & 369.01 \\
\hline 2 & $25^{0} 20^{\prime} 09^{\prime \prime}$ & $85^{0} 58^{\prime} 46^{\prime \prime}$ & 9.66 & 26.63 & 63.71 & Clayey & 8.16 & 0.23 & 163.07 & 38.00 & 327.22 \\
\hline 3 & $25^{0} 21^{\prime} 08^{\prime \prime}$ & $85^{\circ} 57^{\prime} 55^{\prime \prime}$ & 8.97 & 25.09 & 65.94 & Clayey & 7.58 & 0.17 & 175.62 & 42.99 & 324.56 \\
\hline 4 & $25^{0} 21^{\prime} 51^{\prime \prime}$ & $85^{0} 57^{\prime} 28^{\prime \prime}$ & 9.89 & 27.15 & 62.96 & Clayey & 8.16 & 0.21 & 138.00 & 48.00 & 381.44 \\
\hline 5 & $25^{0} 22^{\prime} 38^{\prime \prime}$ & $85^{\circ} 22^{\prime} 10^{\prime \prime}$ & 10.18 & 27.81 & 62.01 & Clayey & 8.21 & 0.23 & 163.07 & 35.00 & 286.83 \\
\hline 6 & $25^{0} 22^{\prime} 65^{\prime \prime}$ & $85^{0} 52^{\prime} 22^{\prime \prime}$ & 9.34 & 25.92 & 64.74 & Clayey & 7.89 & 0.19 & 150.52 & 29.00 & 341.36 \\
\hline 7 & $25^{0} 24^{\prime} 46^{\prime \prime}$ & $85^{0} 51^{\prime} 13^{\prime \prime}$ & 9.24 & 25.69 & 65.08 & Clayey & 7.81 & 0.18 & 163.07 & 44.27 & 369.48 \\
\hline 8 & $25^{0} 28^{\prime} 36^{\prime \prime}$ & $85^{\circ} 30^{\prime} 27^{\prime \prime}$ & 10.19 & 27.83 & 61.97 & Clayey & 8.62 & 0.24 & 150.52 & 34.00 & 357.06 \\
\hline 9 & $25^{0} 25^{\prime} 01^{\prime \prime}$ & $85^{\circ} 49^{\prime} 09^{\prime \prime}$ & 9.27 & 25.77 & 64.95 & Clayey & 7.84 & 0.18 & 175.62 & 44.46 & 296.19 \\
\hline 10 & $25^{0} 23^{\prime} 40^{\prime \prime}$ & $85^{0} 49^{\prime} 28^{\prime \prime}$ & 9.61 & 26.52 & 63.87 & Clayey & 8.12 & 0.20 & 175.62 & 46.05 & 316.28 \\
\hline \multicolumn{12}{|c|}{$\begin{array}{l}\text { Ground truth data } \\
\text { (Based on conversion of IHS to RGB image of the satellite data, prediction of distinct tone and textural analysis of the soil samples) }\end{array}$} \\
\hline 1 & $25^{0} 26^{\prime} 18^{\prime \prime}$ & $85^{\circ} 30^{\prime} 59^{\prime \prime}$ & 7.43 & 31.32 & 61.25 & Clayey & 7.21 & 0.15 & 175.62 & 32.04 & 301.05 \\
\hline 2 & $25^{0} 26 ' 34^{\prime \prime}$ & $85^{\circ} 31^{\prime} 16^{\prime \prime}$ & 5.24 & 32.32 & 62.44 & Clayey & 7.56 & 0.17 & 188.16 & 33.82 & 309.15 \\
\hline 3 & $25^{0} 26^{\prime} 31^{\prime \prime}$ & $85^{0} 30^{\prime} 40^{\prime \prime}$ & 9.42 & 30.78 & 59.80 & Clayey & 7.02 & 0.15 & 163.07 & 38.26 & 319.95 \\
\hline 4 & $25^{0} 25^{\prime} 47^{\prime \prime}$ & $85^{\circ} 27^{\prime} 32^{\prime \prime}$ & 7.97 & 32.84 & 59.19 & Clayey & 7.74 & 0.18 & 150.52 & 42.72 & 295.65 \\
\hline 5 & $25^{0} 27^{\prime} 16^{\prime \prime}$ & $85^{\circ} 26^{\prime} 59^{\prime \prime}$ & 8.21 & 33.50 & 58.29 & Clayey & 7.97 & 0.19 & 163.07 & 31.15 & 287.55 \\
\hline 6 & $25^{0} 17^{\prime} 43^{\prime \prime}$ & $84^{0} 48^{\prime} 12^{\prime \prime}$ & 6.54 & 31.61 & 61.85 & Clayey & 7.31 & 0.16 & 188.16 & 25.81 & 291.6 \\
\hline 7 & $25^{0} 17^{\prime} 59^{\prime \prime}$ & $84^{0} 47^{\prime} 48^{\prime \prime}$ & 8.60 & 31.38 & 60.02 & Clayey & 7.23 & 0.16 & 163.07 & 39.40 & 322.65 \\
\hline 8 & $25^{0} 19^{\prime} 54^{\prime \prime}$ & $84^{0} 51^{\prime} 06^{\prime \prime}$ & 8.22 & 33.53 & 58.25 & Clayey & 7.98 & 0.21 & 175.62 & 30.26 & 301.05 \\
\hline 9 & $25^{0} 21^{\prime} 01^{\prime \prime}$ & $84^{0} 49^{\prime} 13^{\prime \prime}$ & 11.24 & 31.47 & 57.29 & Clayey & 7.26 & 0.16 & 138.00 & 39.57 & 322.65 \\
\hline 10 & $25^{0} 21^{\prime} 07^{\prime \prime}$ & $84^{0} 48^{\prime} 53^{\prime \prime}$ & 7.75 & 32.21 & 60.04 & Clayey & 7.52 & 0.17 & 150.52 & 40.98 & 332.10 \\
\hline
\end{tabular}


Table.2 The percentage distribution of clay soils under different blocks in Patna district

\begin{tabular}{|c|c|c|c|}
\hline $\begin{array}{l}\text { Different CD blocks under } \\
\text { Patna district of Bihar }\end{array}$ & $\begin{array}{l}\text { Geog. Area } \\
\left(\mathrm{km}^{2}\right)\end{array}$ & $\begin{array}{l}\text { Area under clay soil } \\
\text { patches }\left(\mathbf{k m}^{2}\right)\end{array}$ & $\begin{array}{l}\text { Percentage of clay } \\
\text { soil patches }\end{array}$ \\
\hline Maner & 170.7 & 44.25 & 7.01 \\
\hline Dinapur-Cum-Khagaul & 124.46 & 2.75 & 0.44 \\
\hline Patna - Rural & 156.66 & 3.14 & 0.50 \\
\hline Sampat & 65.35 & 8.54 & 1.35 \\
\hline Phulwari & 106.47 & 7.43 & 1.18 \\
\hline Bihta & 193.92 & 8.01 & 1.27 \\
\hline Naubatpur & 167.74 & 36.38 & 5.76 \\
\hline Bikram & 148.15 & 12.78 & 2.02 \\
\hline Dulhin Bazar & 110.68 & 23.94 & 3.79 \\
\hline Paliganj & 237.75 & 66.04 & 10.46 \\
\hline Masaurhi & 202.43 & 30.02 & 4.75 \\
\hline Dhanarua & 185.55 & 14.54 & 2.30 \\
\hline Punpun & 128.75 & 26.4 & 4.18 \\
\hline Fatuha & 126.36 & 11.09 & 1.76 \\
\hline Daniawan & 65.1 & 7.49 & 1.19 \\
\hline Khusrupur & 63.39 & 3.71 & 0.59 \\
\hline Bakhtiyarpur & 196.83 & 62.51 & 9.90 \\
\hline Athmalgola & 40.25 & 7.72 & 1.22 \\
\hline Belchhi & 68.67 & 8.61 & 1.36 \\
\hline Barh & 109.59 & 28.85 & 4.57 \\
\hline Pandarakh & 204.89 & 70.23 & 11.12 \\
\hline Ghoswari & 139.83 & 66.17 & 10.48 \\
\hline Mokama & 191.32 & 80.78 & 12.79 \\
\hline Total & 3204.84 & 631.38 & 100.00 \\
\hline
\end{tabular}

Graph.1 Percentage of sand, silt and clay in observed and predicted soil samples

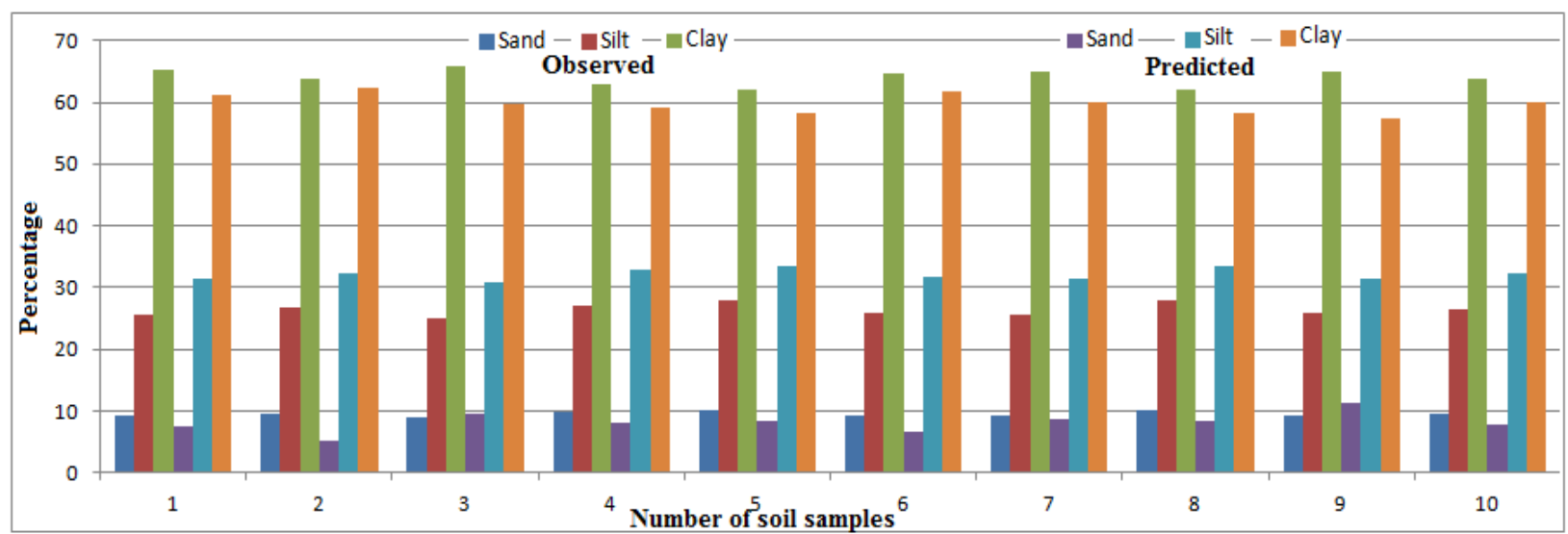


Fig.1 Flow chart showing detailed methodology

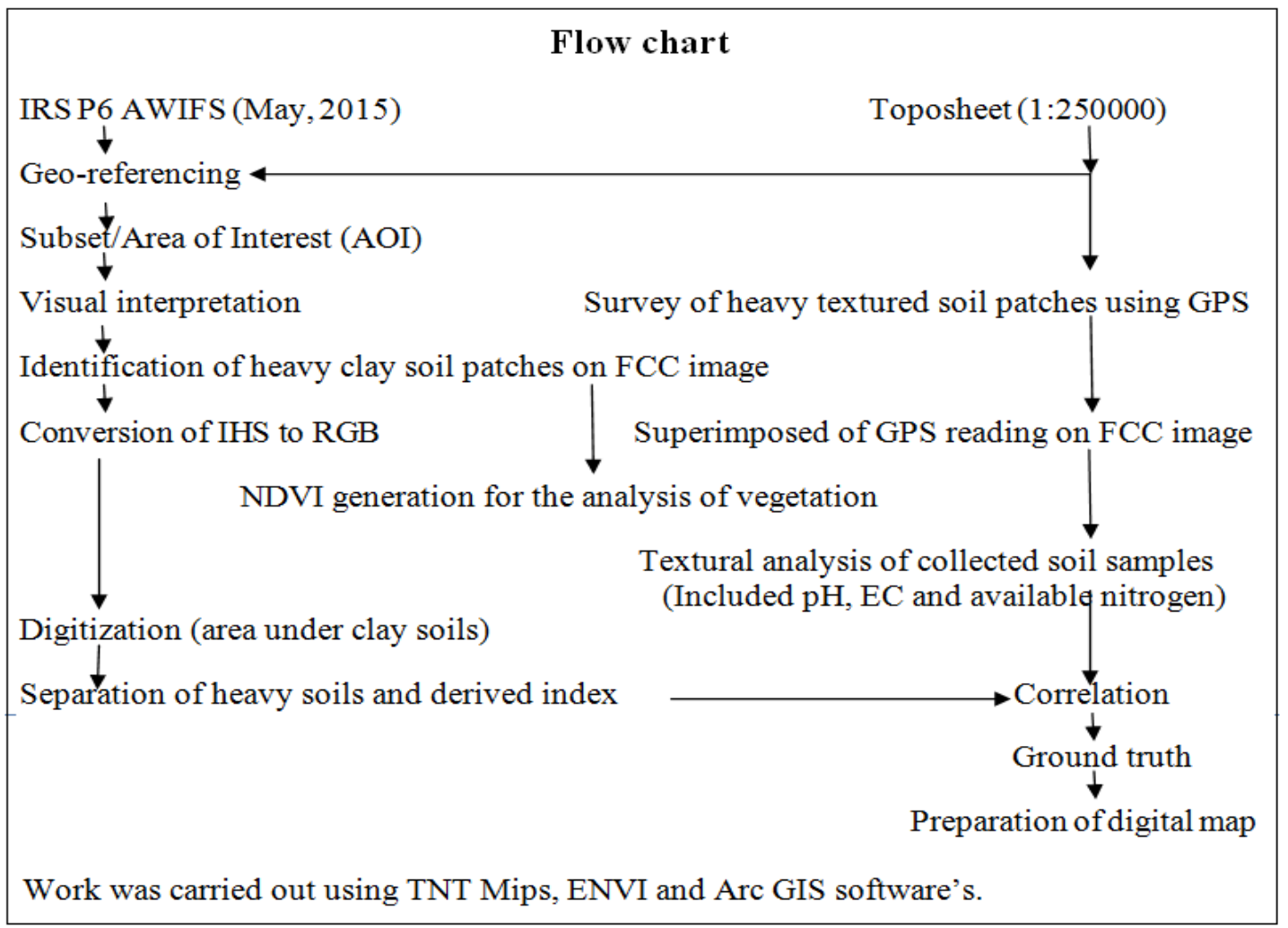

Fig.2 False Colour Composite image of Patna district

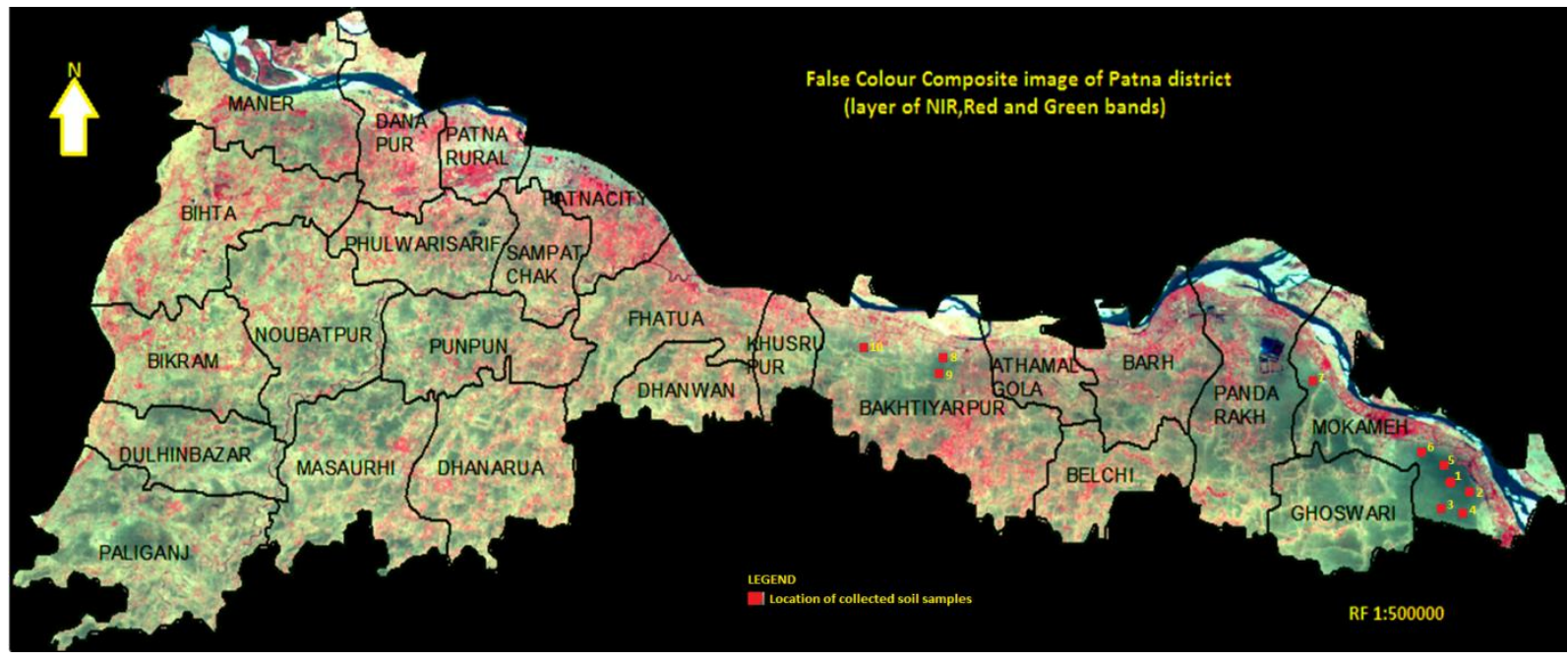


Fig.3 Spectral graph of heavy clay soils, sand patches and water bodies

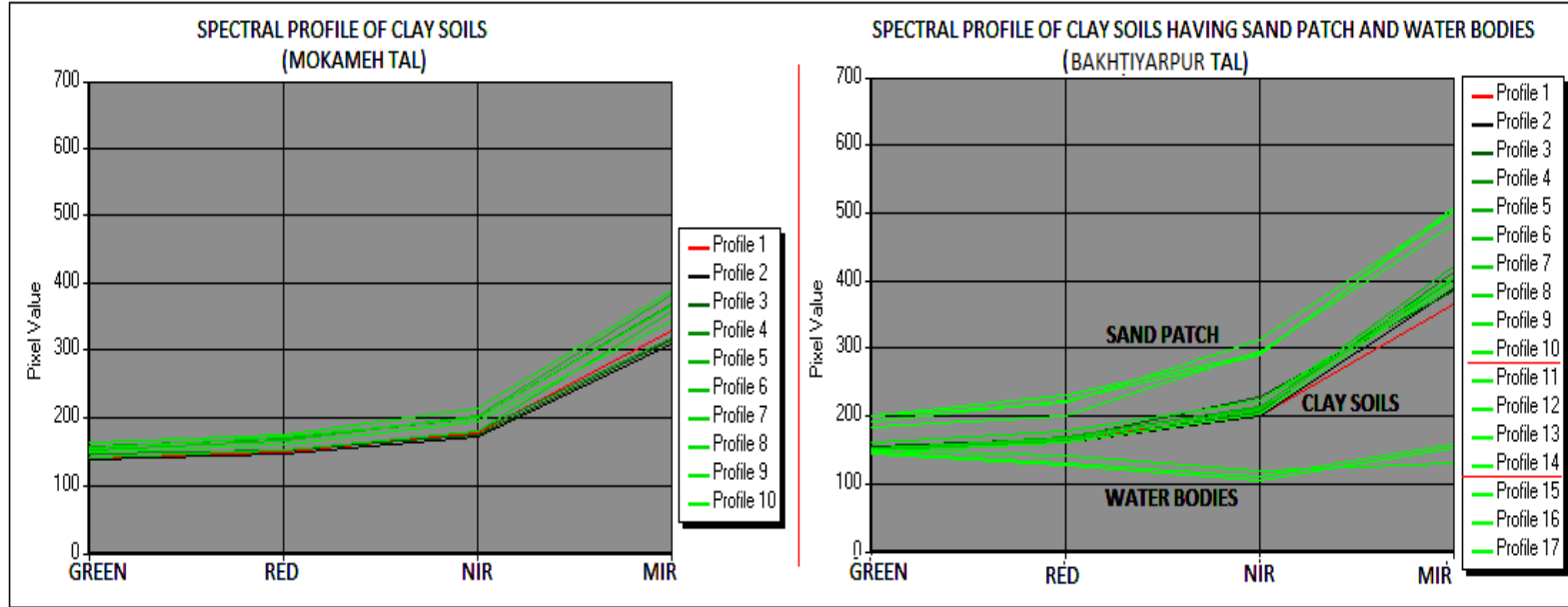

Fig.4 Tree less ecology under heavy clay soils

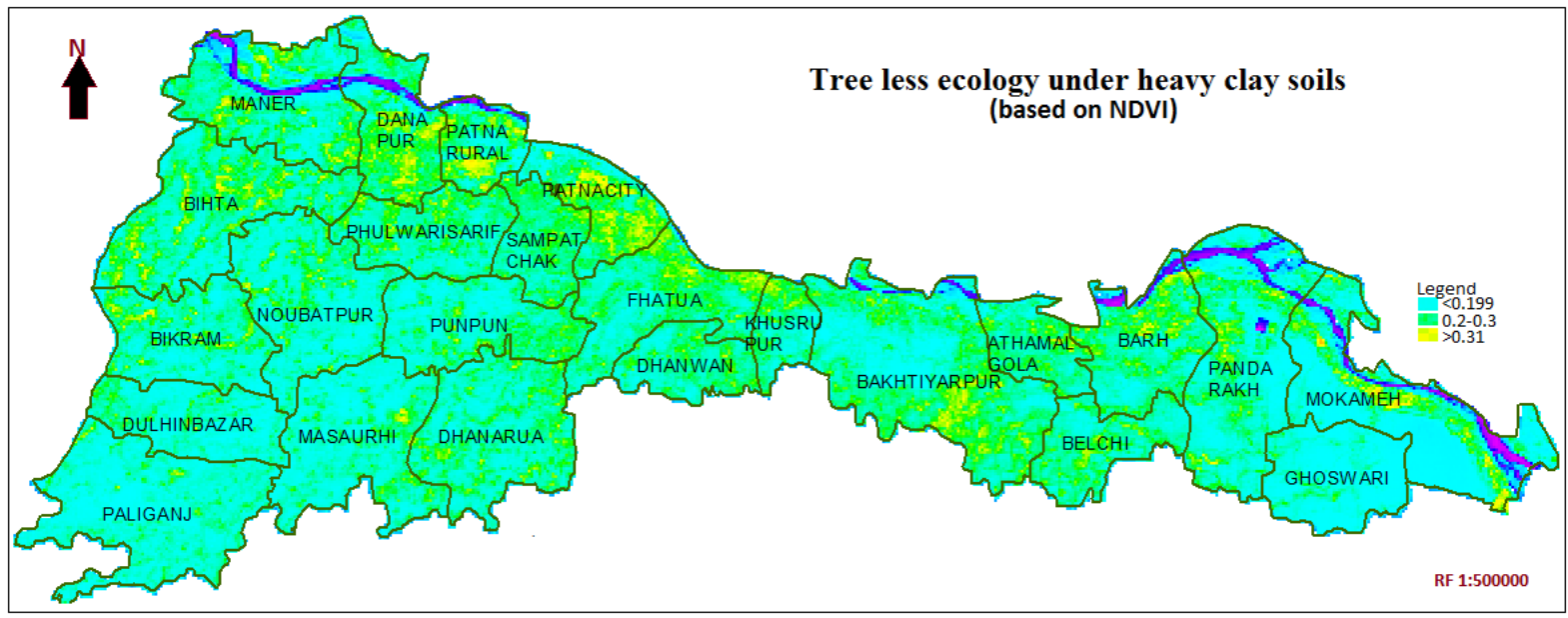

Fig.5 Signature of clay soils in blue tone

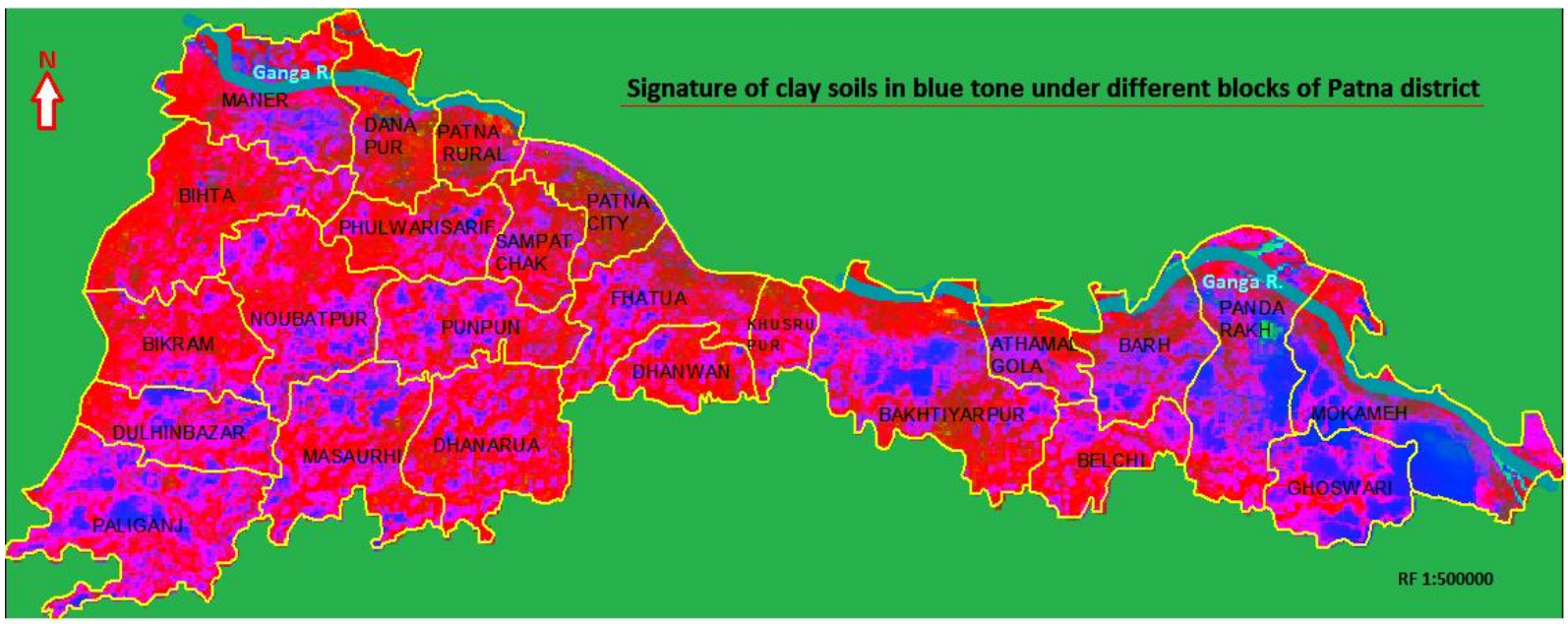


Fig.6 Geographical area of clay soils

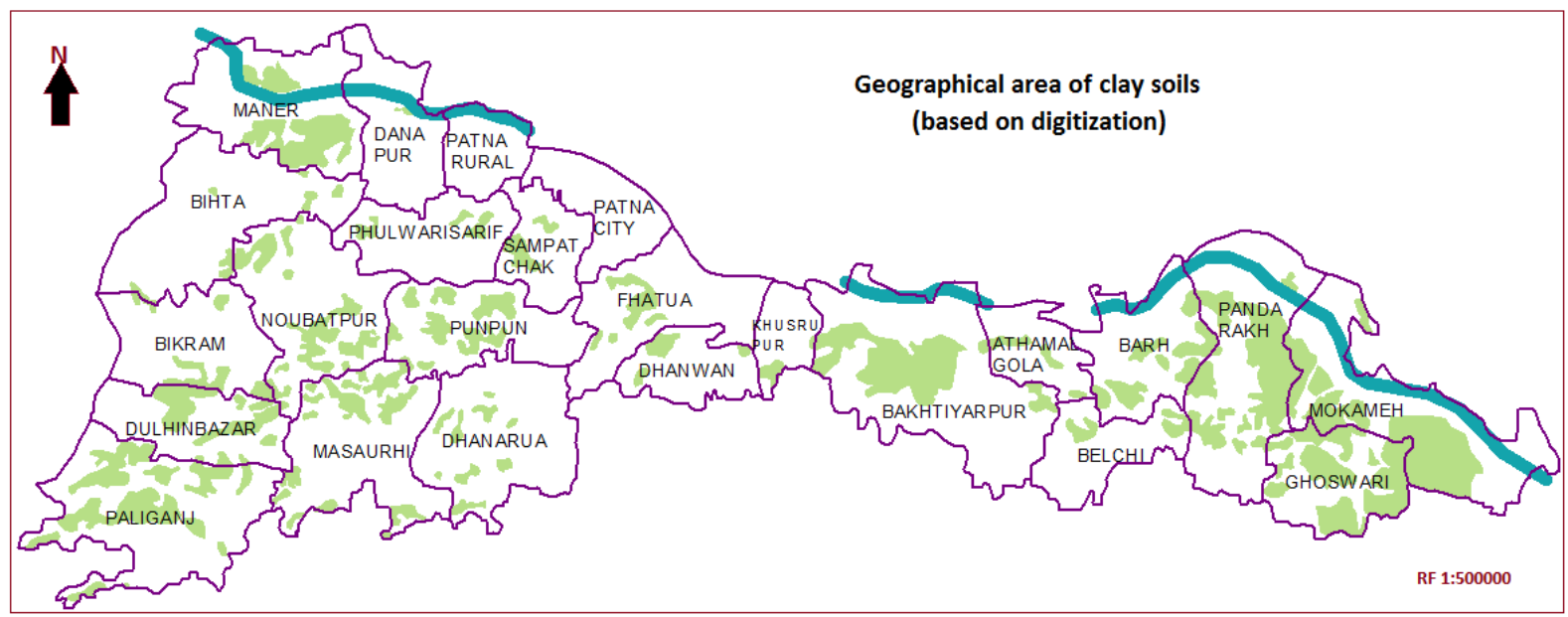

Based on distinct blue tone that was associated with signature of clay soils in Maranchi, Mokameh and Bakhtiarpur Tal, randomly ten soils samples with GPS reading from different locations of Paliganj block were collected to cross check the availability of clay soils in new locations. In continuation of cross checking the tone and validation the data was plotted (Table 1). (Weber and Dunno, 2001) reported that displayed as a map of classified values or results may be helpful for resource managers or scientists for the evaluation the landscape in an accurate and cost effective manner. Soil texture, Soil $\mathrm{pH}$ and EC were also analyzed in the laboratory of the cross checked data and their results were summarized for their comparative study. Result towards percentage of sand, silt and clay in both cases was demonstrated on bar diagram (Graph 1). Blue tone (fallen under clay soils) was digitized in GIS domain for the calculation of geographical area (Fig. 6). Based on research finding, only $631.38 \mathrm{~km}^{2}(19.7 \%)$ of the total geographical area $\left(3204.84 \mathrm{~km}^{2}\right)$ was traced out under clay soils which are neutral to slightly alkaline range of soil $\mathrm{pH}$ and percentage of total geographical area under clay soil patches was marked in Mokameh (12.79\%) consequently Pandarakh (11.12\%), Ghoswari (10.48\%), Pali $(10.46 \%)$ and Bakhtiyarpur $(9.90 \%)$ blocks. However, low geographical coverage of clay soil patches was traced out in Patna rural (0.50\%), Danapur-Khagaul (0.44\%),
Khusrupur (0.59\%), Daniyawan (1.19\%) and Bihta (1.27\%) blocks (Table 2).

In conclusion, model is based on digital image processing technique, whereas spectral enhancement process by using of AWiFS data was initiated to fulfil the objective. Converted RGB image indicated the clear cut demarcation of clay soil patches from surrounding in blue tone which was governed by spectral bands. Research findings may be helpful for clay soil inventory and mapping under low land topography.

\section{Acknowledgements}

Department of Science and Technology, New Delhi is thankfully acknowledged for the financial assistance of the research project (SB/EMEQ-173/2013). Chairman, Department of Soil Science \& Agricultural Chemistry, BAC, Sabour is acknowledged for his valuable suggestions, providing laboratory facilities and B.A.U. communication number 584/2019.

\section{References}

Carper, W.J., Lillesand, T.M. and Kiefer, R.W. 1990. The Use of Intensity-HueSaturation Transformations for Merging SPOT Panchromatic and Multispectral Image Data, Photo-grammetric 
Engineering Remote Sensing 56(4): 459467

Gary Shaw, A., and Hsiao-hua Burke, K. 2003. Spectral Imaging for Remote Sensing, Lincon Laboratory Journal, Volume 14

Gomez Viscarra, C.R., Rossel, A. and Mc Bratney, A.B. 2008. Soil organic carbon prediction by hyper-spectral remote sensing and field vis-NIR spectroscopy: an Australian case study. Geoderma 146, 403-411.

Hubbard, B.E., Crowle, J.K. and Zimbelman, D.R. 2003. Comparative alteration mineral mapping using visible to shortwave infrared (0.4-2.4 $\mu \mathrm{m})$ Hyperion, ALI, and ASTER imagery, IEEE, Transactions on geo science and remote sensing, 41(6 PART I), 14011410.

Jackson, M.L. 1973. Soil Chemical Analysis, Prentice- hall of India Pvt. Ltd, New Delhi, pp.40.

Kristof, S.J., Baumgardner, M.F., Weismiller, K.A. and Davis, S. 1980. Application of multispectral reflectance studies of soils. In: Proceedings of 6th Annual Symposium: Machinery Processing of Remotely Sensed Data and Soil Informational Systems, Remote Sensing and Soil Survey, 52-62. West Laffayette, Indiana.

Laliberte, S.A. and Rango, A. 2008. Monitoring with Unmanned Aircraft Imagery Incorporation of Texture, Intensity, Hue, and Saturation for Range land, New Mexico State University, USDA ARS, GEOBIA, Calgary, AB, Aug 6-7.

Lillesand, M., Ralph, T., Kiefer, W., Jonathan, W. and Chipman. 2005. Remote Sensing and Image Interpretation, Fifth edition. Wiley, New York.

Manchanda, M.L., Mand, K. and Tiwari, A.K. 2002. Soil survey and mapping using remote sensing, Tropical Ecology, 43; 6174.

Pouget, J.M., Madeira, E., Floch, L. and Kamal. S. 1990. Caracteristiques spectrales des surfaces sableuses de la region cot\&e Nord-Ouest de I'Egypte: Application aux don\&es satellitaires SPOT. In: 2eme Joum Ces de T\&detection: Caracterisation et suivi des milieux terrestres en regions arides et tropicales. 4-6/12/1990. Ed. ORSTOM, Collection Colloques et Seminaires, Paris, pp.27-38.

Rouse, J.W. 1973. Monitoring vegetation systems in the Great Plains with ERTS. In Third ERTS, Symposium.

Singh, R.B., Mahtab, A. and Ajai. 2009. Target reparability analysis for resourcesat1AWiFS data. Journal of Geomatics, 19: 19-22.

Viscarra, R.A., Rossel, S., Cattle, A. and Fouad, Y.O. 2009. In situ measurements of soil colour, mineral composition and clay content by vis-NIR spectroscopy. Geoderma, 150: 253-266

Weber, M.R. and Dunno, G.A. 2001. Riparian vegetation mapping and image processing techniques, Hopi Indian reservation, Arizona, Photogrammetric Engineering and remote sensing, 67(2): 179-186

Zhang, Z., Wang, X., Zhao, X., Liu, B., Yi, L., Zuo, L., Wen, Q., Liu, F., Xu, J. and Hu, S. 2014. A 2010 update of national land use/cover database of china at 1:100000 scale using medium spatial resolution satellite images. Remote Sensing of Environment, 149(0): 142 - 154.

\section{How to cite this article:}

Binod Kumar Vimal, Sunil Kumar, Amit Kumar Pradhan, Ragini Kumari, Hena Parveen and Sanjeev Kumar Gupta. 2019. Remote Sensing and GIS based Mapping of Clay Soils-A Case Study of Patna District, Bihar, India. Int.J.Curr.Microbiol.App.Sci. 8(04): 346-354.

doi: https://doi.org/10.20546/ijcmas.2019.804.038 